\title{
USING TVD SIMULATION TO IMPROVE COLLABORATION
}

\author{
Muktari Musa ${ }^{1}$, Christine Pasquire ${ }^{2}$, and Alan Hurst ${ }^{3}$
}

\begin{abstract}
Target Value Design (TVD), a lean approach, has been implemented successfully in the past decade in various countries and its process mandates the collaboration of project participants. However, issues of adapting collaborative practices and the time it takes firsttime users to understand TVD practices have been a challenge in TVD projects. Recently, there has been an increase in the creation, reinvention and use of simulations and serious games to teach TVD and other lean principles to project stakeholders encountering them for the first time.

The 50 minute version of the simulation game developed in Texas A \& M University was used to illustrate TVD practice and collaboration in this study. The study used 24 industry stakeholders from a reputable real estate developer during the implementation of TVD on a live project in Nigeria.

The results reported that the simulation is effective in illustrating the practices of TVD including collaboration and designing to set targets. Finally, this study recommends the inclusion of the TVD simulation game in training and workshops for project team before the commencement of construction projects because it demonstrated to be a simple and practical method of understanding collaboration and TVD practices.
\end{abstract}

\section{KEYWORDS}

Lean construction, simulation game, collaboration, target costing, target value delivery.

\section{INTRODUCTION}

Target Value Design (TVD) emerged from lean construction and serves as a strategic pathway for achieving more collaboration by adopting value perceived by the client (specific design criteria, cost, schedule) as a driver of design (Oliva et al., 2016; Kim and Lee 2010). Essential to TVD is the practice of designing to targets rather than designing, then preparing budgets, schedules, etc. which leads to rework, change-orders, and re-

1 PhD Research Student, School of Architecture, Design and Built Environment, Nottingham Trent University, United Kingdom. +447436554017 muktari.musa@my.ntu.ac.uk

2 Professor, School of Architecture, Design and Built Environment and Director Centre for lean Projects, Nottingham Trent University, UK. +44(0) 1158482095 christine.pasquire@ ntu.ac.uk

3 Senior Lecturer, School of Architecture, Design and Built Environment, Nottingham Trent University, United Kingdom. +44(0) 1158482878 alan.hurst@ntu.ac.uk 
pricing, thus making it unaffordable and off-target for stakeholders. Collaboration is one of the foundational principles of TVD; face-to-face and virtual collaboration are not options in the TVD process, they are necessities. Hyun (2012) stated that TVD process mandates the collaboration of project participants. However, issues of adopting collaborative practices have been observed to be a prominent challenge in TVD projects, this may be predominantly due to difficulty in developing trust within the project environment, lack of early involvement of subcontractor and suppliers, and lack of interaction among estimation and design teams (Do et al., 2015b; Oliva et al., 2016). Additionally, successful implementation of TVD by organisations and team members has been hindered due to lack of awareness, the time it takes first time users to understand its principles, the mind shift needed and the cultural and organizational change (Olivia et al., 2016; Do et al., 2015).

Recently, there has been an increase in the creation, reinvention and use of simulations and serious games to teach TVD and other lean principles to project team stakeholders encountering them for the first time. This can enhance learning in an applied setting (Rybkowski, 2017; Pollesch et al., 2017). Munankami (2012) developed a TVD simulation game to illustrate TVD principles. TVD simulation and games help to create awareness and build teamwork and trust required for collaboration. Available studies on the simulation game have neither shown the iterative process in TVD nor reported the impact of the simulation game on a live project. They also have not emphasised the need for collaboration by discussing the interrelationship between the levels of collaboration. cooperation, coordination coalition and networking. This paper seeks to:

- Adopt the simulation game on a case study project with the hope of mitigating the aforementioned challenges and report the findings while identifying the differences between environments with and without collaboration

- Emphasise the need for collaboration by discussing the interrelationship between collaboration, cooperation, coordination coalition and networking.

- Report the iterative aspect of redesigning to set targets encountered during the simulation where two teams exceeded the target leading to a second attempt; as well as participants interviewed after the live implementation of TVD.

\section{LITERATURE REVIEW}

\section{TVD Simulation Game}

A TVD simulation game was developed by Munankami (2012) in Texas A \& M University to illustrated TVD principles. The game uses the same concepts of Peter Skillman and Tom Wujec's "Marshmallow Challenge" but applies TVD processes (Ebbs 2015). Since its development, the simulation has been tested at the Department of Construction Sciences of Texas A \& M University. Rybkowski et al., (2016) who tested it on students and professionals, stated that most people that have tested and played it reported that it effectively illustrates and teaches TVD. They also advocated for additional testing of the simulation in projects.

Other researchers that have used the game include; Carolina Asensio Oliva in 2014; the Associated Schools of Construction Conferences, College Station, TX in 2015; Tobias 
Guller in Germany (lean consultant) who translated it into German; and Centre for Lean Projects 4th Annual Research Showcase, Nottingham Trent University in 2019 where the moods of the participants were reported after both rounds.

A review of the literature on testing and application of the simulation reveals that the simulation places emphasis on collaboration and cooperation. For example, Munankami (2012) noted that the game was effective when tested, however, he suggested that owners, designers, and contractors should be separated in the first round to help participants think about the value of cooperation during the discussion and some terms should be explained properly. De Melo (2015) also tested the simulation on an exploratory case study to understand the mindset of construction-minded individuals who are willing to apply target costing in Brazil. Ebbs (2015) tested the simulation at the Boise State University workshop to prepare 30 practising professionals for the application of TVD on an actual project. He noted the game illustrates cooperation, competition, team building, collaboration, creativity, innovation, and design within budget constraints.

The literature reviewed further shows that the various studies available have not highlighted the concepts of cooperation, collaboration, coordination, coalition, and networking after round one of the simulation as collaboration is discussed in only after round two. They also do not report findings of the iterative aspect of redesigning to targets in round two. None of the several researchers that have conducted the simulation reported their findings after implementation of TVD on a project by participants of the simulation game.

\section{THE LEVELS AND INTERRELATIONSHIP OF COLLABORATION}

One of the most important discussions in the construction industry and research is the shift towards new collaborative project delivery systems (Hamid and Pardis 2014). Schrage (1990) defines collaboration as "the process of shared creation between two or more individuals with complementary skills interacting to create a shared understanding that none had previously shared or could have come to on their own". This implies that the underlying principle of collaboration is that there must be an interaction between the parties that will culminate in the creation of value to both parties. Attaran and Attaran (2007) maintained that collaboration does not only include the joint working of two or more organisations but three core criteria must be satisfied. These are: (1) having shared common information; (2) ensuring plans are made based on the shared information; and (3) executing the planned task collectively rather than individually.

The term cooperation has been used unknowingly to mean collaboration, which has led to the non-achievement of some so-called collaborative efforts. The Oxford Advanced Dictionary defines cooperation as the "process or the action of working together to the same end". This definition does not show the three core elements of collaboration as identified by Attaran and Attaran (2007). Cooperation could allow information to be shared between organisations, yet each organisation could still be acting independently, without regard for the other.

Coordination is the act of managing and unifying different activities on a project with multiple tasks, participants or organisations (O'Brien et al., 1995). The focus of coordination is to define a formal approach to organising how operations and activities 
should be conducted, which suggests that coordination is still based on the command and control philosophy. This implies that the mutuality element of collaboration is absent, even though the approach is formal.

Networking is a process that nurtures the exchange of information and ideas among individuals or groups that share a common interest (Investopedia 2017). Page (2018) opined that networking strengthens business connections, ensures fresh ideas, supports the gaining of different perspectives, and develops long-lasting relationships. On the other hand, Gaida and Koliba (2007) argue that networking is the weakest operational form of relational collaboration.

Coalition is defined by Lerbinger (2005) as the interrelating group of organisational actors, who: agree to pursue a common goal; manage their resources in a bid to accomplish this common goal and adopt a mutual strategy in chasing this goal. Foster-Fishman et al., (2001) are of the opinion that one of the important purposes of a coalition is to produce a collaborative capacity among coalition members through the organisational structure and programs of the coalition.

Table 1 shows the relationship between the levels of collaboration. From Table 1 and the prior discussion, it can be concluded that an organisation could practice cooperation and coordination without collaborating. Additionally, cooperation and coordination are processes that will naturally occur in the collaboration process.

Table 1: Relationship between networking, cooperation, coordination, coalition and collaboration

\begin{tabular}{|c|c|c|c|c|c|}
\hline & Networking & Cooperation & Coordination & Coalition & Collaboration \\
\hline \multirow[t]{4}{*}{$\begin{array}{l}\text { Relationship } \\
\text { characteristics }\end{array}$} & $\begin{array}{l}\text {-Aware of } \\
\text { Organisation }\end{array}$ & $\begin{array}{l}\text { - Provide } \\
\text { information to } \\
\text { each other }\end{array}$ & $\begin{array}{l}\text {-Share } \\
\text { information } \\
\text { and resources }\end{array}$ & $\begin{array}{l}\text {-Shared ideas } \\
\text {-Shared } \\
\text { resources }\end{array}$ & $\begin{array}{l}\text {-Members } \\
\text { belong to one system }\end{array}$ \\
\hline & $\begin{array}{l}\text {-Loosely } \\
\text { defined roles }\end{array}$ & $\begin{array}{l}\text {-Somewhat } \\
\text { defined roles }\end{array}$ & -Defined Roles & & \\
\hline & $\begin{array}{l}\text {-Little } \\
\text { communication }\end{array}$ & $\begin{array}{l}\text {-Formal } \\
\text { communication }\end{array}$ & $\begin{array}{l}\text {-Frequent } \\
\text { communication }\end{array}$ & $\begin{array}{l}\text {-Frequent and } \\
\text { prioritised } \\
\text { communication }\end{array}$ & $\begin{array}{l}\text {-Frequent } \\
\text { communication } \\
\text { characterized by } \\
\text { mutual trust }\end{array}$ \\
\hline & $\begin{array}{l}\text { - All decisions } \\
\text { are made } \\
\text { independently }\end{array}$ & $\begin{array}{l}\text {-All decisions } \\
\text { are made } \\
\text { independently }\end{array}$ & $\begin{array}{l}\text {-Some shared } \\
\text { decision } \\
\text { making }\end{array}$ & $\begin{array}{l}\text {-All members } \\
\text { have a vote in } \\
\text { decision- } \\
\text { making }\end{array}$ & $\begin{array}{l}\text {-A consensus is } \\
\text { reached on all } \\
\text { decisions }\end{array}$ \\
\hline
\end{tabular}

(Source: Frey et al., 2006)

It has been observed that interaction naturally occurs between construction project stakeholders before the delivery of the construction product, however, such interaction based on the old sequential model of project delivery cannot be viewed as collaboration since each team works independently of each other (Shelbourne et al., 2012). 


\section{METHODOLOGY}

The materials, methods, and instructions for the 50 minutes version of the game developed by Munankami (2012) were adopted for this paper with few modifications. The study used 24 industry stakeholders from a reputable real estate developer in Nigeria, it was conducted during the workshop and training exercise at the initiation phase of a live project. The simulation concluded with interviews and survey of the participants.

After the simulation game, TVD was applied to a live project. The implementation of TVD was carried out on a project in Abuja, federal capital territory (FCT) of Nigeria. The project is the development of a self-sufficient and affordable city on 72 hectares, composed of 3,500 units of various house types. It also includes infrastructure covering a $7 \mathrm{~km}$ dual carriage road to connect with the existing road network, $10 \mathrm{~km}$ internal roads; sewer and stormwater drainages. The detail description of the TVD implementation process is beyond the scope of this paper. At the end of the TVD implementation on the live project, 14 of the 24 simulation game participants were interviewed.

Simulation Rounds: Two rounds of the simulation were done. Round one simulated traditional design-bid-build (DBB) processes while Round two simulated TVD processes. The simulation required four teams, each comprising three groups: owners, designers, and constructors. They were required to use only supplied materials to build a free-standing table-top tower that is two feet tall, no more than two inches out of plumb and capable of holding a marshmallow at the top. Each round was expected to last about 15-20 minutes.

Round one: The team groups worked in separate rooms to design, the owner approves, and the towers were constructed without regard for cost during the design process.

Costing: Costs were calculated only after the towers were completed, and teams were given a costing sheet as seen in Table 2 . The following were calculated: market cost (122.38); allowable cost (97.90); target cost (86.75).

After round one, the facilitator asked the teams if they had collaborated and how they did. They answered in the affirmative, stating that they collaborated by providing information to team members and making decisions within individual groups.

Table 2: Round one; Establishing Target Cost

\begin{tabular}{|c|c|c|c|c|c|c|c|c|c|}
\hline \multirow[b]{2}{*}{ Materials } & \multirow[b]{2}{*}{ Unit cost } & \multicolumn{2}{|c|}{ Team Abuja } & \multicolumn{2}{|c|}{ Team Lagos } & \multicolumn{2}{|c|}{$\begin{array}{c}\text { Team Port } \\
\text { Harcourt }\end{array}$} & \multicolumn{2}{|c|}{ Team Ibadan } \\
\hline & & Units & Subtotal & Units & Subtotal & Units & Subtotal & Units & Subtotal \\
\hline Spaghetti sticks & $\# 1.00$ & 13 & $\# 13.00$ & 0 & & 0 & $\#-$ & 0 & $\#-$ \\
\hline Coffee stirrers & $\# 5.00$ & 4 & * 20.00 & 0 & $\# \quad-$ & 3 & \# 15.00 & 4 & \# 20.00 \\
\hline Drinking straws & $\# 2.00$ & 12 & A 24.00 & 0 & $\# 16.00$ & 12 & \# 24.00 & 12 & \# 24.00 \\
\hline Bamboo skewers & A 3.00 & 12 & A 36.00 & 8 & $\# 132.00$ & 15 & \# 45.00 & 12 & A 36.00 \\
\hline Masking Tape & \# 0.50 & 22 & $* 11.00$ & 44 & A 9.00 & 18 & $\# 9.00$ & 22 & $\# 11.00$ \\
\hline Subtotal & & & A104.00 & & A157.00 & & $\# 93.00$ & & $\# 91.00$ \\
\hline Profit (10\%) & & & A 10.40 & & $\# 15.70$ & & \# 9.30 & & \# 9.10 \\
\hline TOTAL & & & A114.40 & & A 72.70 & & \#102.30 & & \#100.10 \\
\hline \multicolumn{3}{|c|}{ Market cost (= ave. of all towers) } & A122.38 & & & & & & \\
\hline \multicolumn{3}{|c|}{ Allowable cost $(=20 \%<$ Market cost $)$} & \# 97.90 & & & & & & \\
\hline
\end{tabular}


Teams declared target cost $(<$ allowable)

Target Cost (= ave. of all declared TCs)
$* 90.00$

$\# 89.00$

\#85.00

\#3.00

The researcher then informed the teams that they were cooperating not collaborating. He noted that 'cooperation' has been wrongly used to mean 'collaboration' which has led to non-achievement of some so-called collaborative efforts. He noted that team members should work collaboratively and consensus be reached in all decisions by all stakeholders. He then went further to give the participants talk on cooperation, coordination, networking, coalition and collaboration. In preparation for the second round, the talk highlighted the differences between cooperation, coordinating, coalition, networking and collaboration to the teams.

Round two: In the second round, designs, approval, and construction were done collaboratively with all team members, with the aim of designing to target cost. Two teams (Abuja and Lagos) exceeded the cost target of 86.75 (see table 3).

Table 3: Round two calculated design cost for all teams

\begin{tabular}{|c|c|c|c|c|c|c|c|c|c|}
\hline \multirow[b]{2}{*}{ Materials } & \multirow[b]{2}{*}{ Unit cost } & \multicolumn{2}{|c|}{ Team Abuja } & \multicolumn{2}{|c|}{ Team Lagos } & \multicolumn{2}{|c|}{$\begin{array}{c}\text { Team Port } \\
\text { Harcourt }\end{array}$} & \multicolumn{2}{|c|}{ Team Ibadan } \\
\hline & & Units & Subtotal & Units & Subtotal & Units & Subtotal & Units & $\begin{array}{l}\text { Subtota } \\
\text { | }\end{array}$ \\
\hline Spaghetti sticks & $\# 1.00$ & 0 & $\#$ & 0 & $\#$ & 0 & \# & 0 & $\#-$ \\
\hline Coffee stirrers & $\# 5.00$ & 0 & $\#-$ & 0 & \# - & 0 & $\#-$ & 0 & A - \\
\hline Drinking straws & A 2.00 & 19 & $\# 38.00$ & 6 & \# 12.00 & 0 & \# - & 3 & A 6.00 \\
\hline Bamboo skewers & $\# 3.00$ & 13 & \# 39.00 & 21 & \# 63.00 & 15 & \# 45.00 & 12 & $\# 36.00$ \\
\hline Masking Tape & $\# 0.50$ & 6 & $\# 3.00$ & 10 & \# 5.00 & 10 & \# 5.00 & 3 & A 1.50 \\
\hline Subtotal & & & $\# 80.00$ & & $\# 80.00$ & & $\$ 50.00$ & & \# 43.50 \\
\hline Profit (10\%) & & & \# 8.00 & & \# 8.00 & & $\# 5.00$ & & A 4.35 \\
\hline TOTAL & & & $\# 88.00$ & & $\# 88.00$ & & $\# 55.00$ & & A 47.85 \\
\hline
\end{tabular}

A second attempt was carried out to redesign to cost by the teams that exceeded the target cost. Cost less than the target cost was achieved at the second attempt after value engineering and brainstorming sessions were used to iteratively redesign to target cost without affecting function and quality (see table 4)

Table 4: Costing redone after the iterative redesign to target cost

\begin{tabular}{|c|c|c|c|c|c|}
\hline & & \multicolumn{2}{|c|}{ Team Abuja } & \multicolumn{2}{|c|}{ Team Lagos } \\
\hline Materials & Unit cost & Units & Subtota & Units & $\begin{array}{l}\text { Subtota } \\
\text { | }\end{array}$ \\
\hline Spaghetti sticks & \# 1.00 & 0 & $\#-$ & 0 & A - \\
\hline Coffee stirrers & A 5.00 & 0 & \# & 0 & \# \\
\hline Drinking straws & \# 2.00 & 15 & $\# 30.00$ & 6 & \# 12.00 \\
\hline Bamboo skewers & A 3.00 & 12 & $\# 36.00$ & 16 & A 48.00 \\
\hline Masking Tape & A 0.50 & 8 & $\# 4.00$ & 8 & A 4.00 \\
\hline Subtotal & & & $\# 70.00$ & & A 64.00 \\
\hline Profit (10\%) & & & \# 7.00 & & \# 6.40 \\
\hline TOTAL & & & $\# 77.00$ & & \# 70.40 \\
\hline
\end{tabular}




\section{RESULTS AND DISCUSSION}

The facilitator conducted interviews and surveys for the participants of the game to assess their experiences playing the simulation and its effectiveness in teaching TVD principles.

\section{Findings From The Post-Simulation InTERViEW}

The participants were asked the following questions after the game:

What were some basic differences between the two rounds? How did the decisionmaking processes differ between the two rounds? Which round was more stressful for you? Which round offered better cooperation? In which real-life circumstances might round one be more appropriate? How about round two?

The respondents' collective answers reveal that less time was spent in the second round compared to the first because of the collaborative working of the team. While the teams' average completion time for round one was 23 minutes, it was 16 minutes for round two. The teams understood the scope of work in round two compared to round one.

The participants noted that all decisions were made independently during round one but in round two, a consensus was reached on all decisions; this shows that in round one, the teams were just cooperating while in round two, ideas were put together collaboratively. Participants considered round one more stressful. They also noted that there was more frequent communication characterised by mutual trust in round two compared to round one.

The participants noted that the round one would be suitable for projects where collaborative practices cannot be adopted and where designs are completed before costing is done. While round two would be suitable for projects with predetermined and benchmarked budget that must be design to and not exceeded. Round two can also be suitable for projects where cost drives the design; where collaborative designing to targets is a requirement. All the respondents agreed the simulation game was very effective in teaching and understanding the principles and practices of TVD. Figure 1 shows the round two towers constructed to target cost

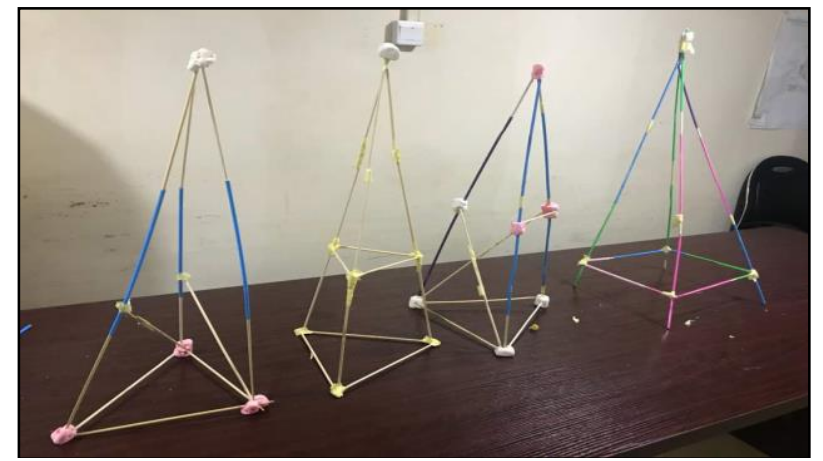

Figure 1: showing the Round two towers constructed to target cost

\section{Findings From The Post-Simulation Questionnaire Survey}

At the end of both rounds, a 5-point Likert scale questionnaire ranging from "not effective" to "extremely effective" was administered to 22 out of 24 participants (92\%). The questions focus on the effectiveness of the simulation in explaining: Q(a) mutual respect and trust; 
$\mathrm{Q}(\mathrm{b})$ mutual benefit and reward; $\mathrm{Q}(\mathrm{c})$ Collaborative innovation and decision-making; $\mathrm{Q}(\mathrm{d})$ early involvement of key partners; Q(e) early goal definition, Q(f) open communication. Results from questionnaire responses are shown in Figure 2.

The analysis of the questionnaire indicated that majority of the respondents reported that the game was very effective in illustrating the following: $\mathrm{Q}$ (a) mutual respect and trust (100\%); Q(b) mutual benefit and reward (91\%); Q(c) Collaborative innovation and decision-making (95\%); Q(d) early involvement of key partners $(87 \%)$; $\mathrm{Q}(\mathrm{e})$ early goal definition (95\%); Q(f) open communication (82\%).

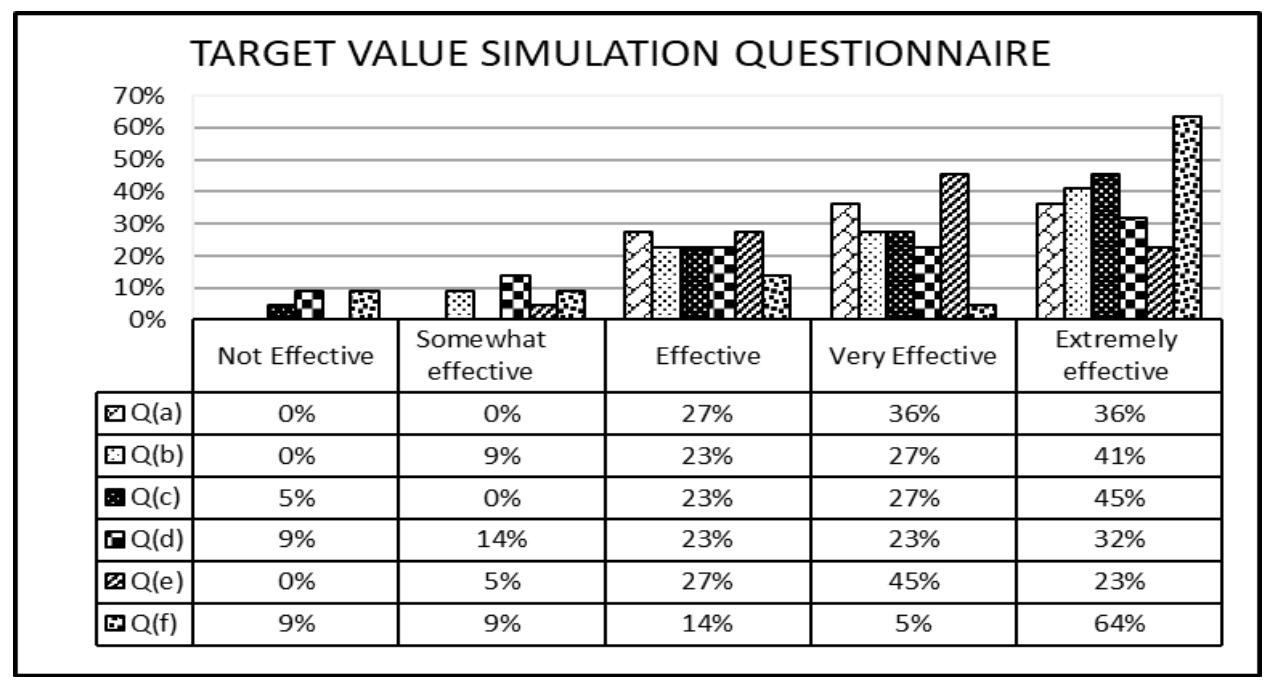

Figure 2 Graph of response from 22 respondents

\section{Findings From a PoSt- TVD IMPLEMENTATION INTERVIEW}

Subsequent to the TVD implementation on the live project, 14 of the 24 simulation game participants were interviewed; representing 58\% of the participants which is a good representation of the total participants of the simulation. Analysis of the interviews indicated all the interviewed participants agree the simulation was explanatory and enabled them to implement TVD successfully. They also reported that the simulation will serve as a support and success factor for the implementation of TVD on any project. The simulation has proven to be a simpler and more practical method of understanding collaboration and TVD practices than formal training and workshops.

It was observed that during the TVD implementation on the live project, team members that participated in the simulation game were assigned to be team heads during cluster formations because they had a better understanding of TVD and performed better than those that did not.

\section{CONCLUSION}

This paper presented a report of the TVD Marshmallow Simulation Game conducted to illustrate the basics of TVD. It further points out the significance of collaborative working through early involvement of key stakeholders. The simulation shows how stakeholders can work collaboratively to bring about innovative design alternatives, steer cost below the 
target, agree on a realistic schedule, the best quality standards and ensure customer satisfaction. Work environments characterised by collaboration is more enjoyable to work in and work takes little time when compared to the environment without collaboration. The study also illustrated the iterative redesigning to a set target in a scenario when initial targets have been exceeded.

The TVD simulation game has demonstrated to be effective in teaching the principles and practices of TVD to first time users; it is also very effective in illustrating mutual respect and trust, collaborative innovation and decision-making. The traditional designbid-Build contracts are suitable for projects where collaborative practices cannot be adopted and when costing is done after designs have been completed, while the TVD approach is suitable for projects with a predetermined and benchmarked budget that must be designed to and not exceeded.

There is a need to conduct discussions on the different levels of collaboration preferably before the commencement of the second round; this is to enable participants to have a better understanding of the various concepts and how to apply them on projects. Also, before the commencement of the game, the specification of the tower to be constructed like the quality, height, and width should be properly stated, otherwise participants may reduce the scope to reduce the cost especially in round two.

Finally, this study recommends the inclusion of the TVD Simulation Game in training and workshops for project team before the commencement of construction projects since it has demonstrated to be a more simple and practical method of understanding collaboration and TVD practices.

\section{ACKNOWLEDGEMENTS}

I wish to express my profound gratitude to Zofia Rybkowski and the entire Texas A\&M University for supplying the instructions and spreadsheet used in the game. I also wish to appreciate the Centre for Lean Projects, Nottingham Trent University.

\section{REFERENCES}

Attaran, M. \& Attaran, S. (2007). Collaborative supply chain management: the most promising practice for building efficient and sustainable supply chains. Business Process Management Journal, 13(3), 390-404.

De Melo R. S. S. (2015). Guidelines for target costing introduction in the real estate products development process. Doctorate thesis presented to the School of Civil Engineering, Architecture and Urban Design, University of Campinas, to obtain the Ph. D. degree in Civil Engineering, in the area of Architecture and Construction.

Do, D., Ballard, G. and Tommelein, I. D. (2015). An Analysis of Potential Misalignment of Commercial Incentives in Integrated Project Delivery and Target Value Design. In: Proc. 23rd Annual. IGLC Conference Perth, Australia, July 29-31, pp. 277-286, available at www.iglc.net.

Do, D., Ballard G., and Tillmann P. (2005b). Part 1 of 5: The Application of TVD in the Design and Construction of the UHS Temecula Valley Hospital. Technical Report Project Production Systems Laboratory University of California, Berkeley 
Ebbs. (2015). Target Value Design and the Marshmallow Team Building Game.

Foster-Fishman, P. G., Berkowitz, S. L., Lounsbury, D. W., Jacobson, S. and Allen, N. A. (2001). Building Collaborative Capacity in Community Coalitions: A Review and Integrative Framework. American Journal of Community Psychology, Vol. 29, No. 2.

Frey, B, et al. (2006) Measuring Collaboration Among Grant Partners. American Journal of Evaluation 27(3), 383-392.

Gajda, R. and Koliba, C. (2007). Evaluating the Imperative of Intra-Organizational Collaboration, A School Improvement Perspective. American Journal of Evaluation, Vol. 28 No. 1, 26-44 DOI: 10.1177/1098214006296198.

Hyun, W. L. (2012). Application of Target Value Design to Energy Efficiency Investments. University of California, Berkeley.

Hamid A. and Pardis, P. (2014). Developing a Framework of Metrics to Assess Collaboration in Integrated Project Delivery. 50th ASC Annual International Conference Proceedings. 1-8.

Investopedia. (2017). Networking. Dotdash publishing family.

Iyer, K. C., and Jha, K. N. (2005). Factors affecting cost performance: evidence from Indian construction projects. Int. Journal of Project Management, 23, 283-295

Kim, Y. and Lee, H.W. (2010). Analyzing User Costs in a Hospital: Methodological Implication of Space Syntax to Support Whole-life Target Value Design. Lean Construction Journal, 11, pp.55-63.

Kochhar, S. (2013). A Conceptual Model for Measuring Coalition Building Effectiveness. A research paper submitted to Institute for Public Relations as part of the Ketchum Excellence in Public Relations Research Award.

Lerbinger, O. (2005). Corporate Public Affairs: Interacting with Interest Groups, Media, and Government (Routledge Communication Series). Routledge.

Munankami, M. B. (2012). "Development and testing of a simulation (game) to illustrated basic principles of Integrated Project Delivery and Target Value Design: A First Run Study," Graduate Thesis, Texas A\&M University, College Station, TX.

O'Brien, W., Fischer, M.A. \& Jucker, J.V. (1995). 'An Economic View of Project Coordination', Construction Management and Economics, 13:393-400.

Oliva, C.A., Granja, A.D., Ballard, G., Melo, R.S.S. (2016). "Assessing Suitability of Target Value Design Adoption for Real Estate Developers in Brazil." In: Proc. 24th Ann. Conf. of the Int'1. Group for Lean Construction, Boston, MA, USA, sect.4 pp. 93102. Available at: <www.iglc.net>.

Oxford English Dictionary. (2018). Rigour. Oxford University Press.

Page, M. (2018). Top 11 benefits of networking. Michael Page International. Australia.

Pollesch, P., Rovinsky, A., Alvarado III, R., and Alves, T.C.L. (2017). "House of Cards a Simulation of Lean Construction Principles" In: LC3 2017 Volume II - Proceedings of the 25th Annual Conference of the International Group for Lean Construction (IGLC), Walsh, K., Sacks, R., Brilakis, I. (eds.), Heraklion, Greece, pp. 373-380. DOI: https://doi.org/10.24928/2017/0212

Rybkowski, Z. K., Munankami, M., Shepley, M. M., and Fernández-Solis, J. L. (2016). "Development and testing of a lean simulation to illustrate key principles of Target 
Value Design: A first run study." In: Proc. 24th Ann. Conf. of the Int'1. Group for Lean Construction, Boston, MA, USA, sect.4 pp. 133-142. Available at: 〈www.iglc.net>.

Rybkowski, Z. K. (2017). Serious Games and Simulations: Transforming Culture to enhance building project delivery. National Institute of Building sciences conference and Expo; Preparing the High-performance workforce.

Schrage, M. (1990). Shared Minds: The New Technologies of Collaboration, New York: Random House.

Shelbourne, M, Sheriff, A., Bouchlagham, D., El-Hamalawa and Yeomans, S. (2012). Collaboration Key concepts. In Bouchlaghem, Collaborative working in construction. London; Spon Press 
Musa, M., Pasquire, C., and Hurst, A

Proceedings IGLC - 27, July 2019, Dublin, Ireland 